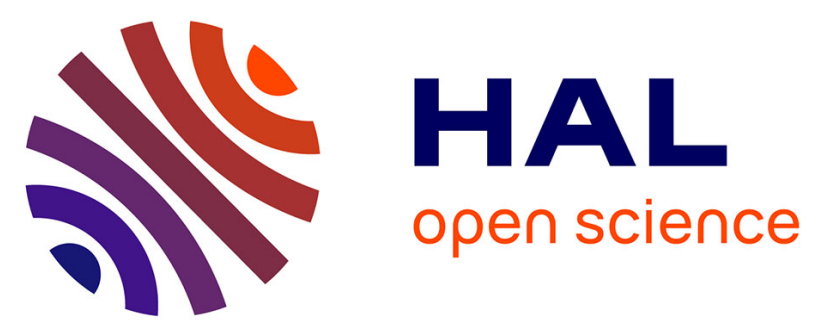

\title{
The management of perineal hernia following abdomino-perineal excision for cancer
}

Karen Bertrand, Jeremie H Lefevre, Ben Creavin, Minh Luong, Clotilde Debove, Thibault Voron, Najim Chafai, Emmanuel Tiret, Yann Parc

\section{- To cite this version:}

Karen Bertrand, Jeremie H Lefevre, Ben Creavin, Minh Luong, Clotilde Debove, et al.. The management of perineal hernia following abdomino-perineal excision for cancer. Hernia, 2020, 24 (2), pp.279-286. 10.1007/s10029-019-01927-7 . hal-03217698

\section{HAL Id: hal-03217698 https://hal.sorbonne-universite.fr/hal-03217698}

Submitted on 5 May 2021

HAL is a multi-disciplinary open access archive for the deposit and dissemination of scientific research documents, whether they are published or not. The documents may come from teaching and research institutions in France or abroad, or from public or private research centers.
L'archive ouverte pluridisciplinaire $\mathbf{H A L}$, est destinée au dépôt et à la diffusion de documents scientifiques de niveau recherche, publiés ou non, émanant des établissements d'enseignement et de recherche français ou étrangers, des laboratoires publics ou privés. 
THE MANAGEMENT OF PERINEAL HERNIA FOLLOWING ABDOMINO

PERINEAL EXCISION FOR CANCER

Karen BERTRAND ${ }^{1}$, Jeremie H. LEFEVRE ${ }^{1}$, Ben CREAVIN ${ }^{2}$, Minh LUONG $^{1}$, Clotilde

DEBOVE ${ }^{1}$, Thibault VORON ${ }^{1}$, Najim CHAFAI ${ }^{1}$, Emmanuel TIRET $^{1}$, Yann PARC ${ }^{1}$.

(1) Departments of Digestive and General Surgery, Hospital Saint-Antoine AP-HP, Sorbonne Université, Paris, France.

(2) Department of Surgery, St Vincent's University Hospital, Elm Park, Dublin 4, Ireland

\section{Original article}

\section{No Funding to declare}

\section{Correspondance and reprint requests:}

Pr Jérémie H. Lefèvre, Department of Digestive Surgery, Hôpital Saint-Antoine, Assistance Publique Hôpitaux de Paris, Université Pierre et Marie Curie, Paris VI, 184 rue du Faubourg Saint-Antoine, 75012, Paris, France

Tel: 00331492825 47, Fax: 0033149282548

e-mail: jeremie.lefevre@aphp.fr

Short running title: Perineal Hernia repair post abdominoperineal resection

Word count: 3354 


\section{INTRODUCTION}

Abdomino-perineal resection (APR) is associated with significant morbidity, of which, perineal hernia $(\mathrm{PH})$ is a late and rare complication. $\mathrm{PH}$ occurs when abdominal organs protrude into the pelvic floor with incidence ranging from $<1 \%$ for symptomatic and $7 \%$ for asymptomatic. However, due to the complexity of diagnosing and under reporting of such complication, the true incidence is unclear. [1-3] . Risk factors associated with this complication include obesity, diabetes, smoking, radiotherapy, extended resection, laparoscopy and method of pelvic reconstruction. With the increasing use of radiotherapy and extralevator resection, the incidence of $\mathrm{PH}$ may increase, with more recent reports suggesting occurrence rates of $12 \%-26 \%[4,5]$.

PH usually occurs within the first 2 post-operative years, with a median interval of ten months $[1,5]$. Its diagnosis is clinical, with a bulging mass or pain and discomfort worse on standing or in the sitting position being the commonest presentations. A CT scan or MRI during oncological follow up can aid in diagnosis, however, patient positioning during scanning (supine) may reduce hernia detection rates. Furthermore, there currently is no established radiological definition of $\mathrm{PH}$.

Complications of PH include urinary dysfunction, skins erosions and bowel obstruction.

Surgical PH repair is indicated based on the severity of the complication along with patient reported discomfort. Many repair options are described in the literature and are based on the approach (perineal, abdominal, combined and laparoscopic) or on the technique (suture, pexy, synthetic and biological mesh or flap). As this is a rare complication of APR, only few studies exist, mainly case reports or studies with low numbers and short follow-up. As a result, no consensus can be established on the optimal surgical management of PH.

The aim of this article was to describe the management of $\mathrm{PH}$, analyze the recurrence and complications rates and compare our center's results with current studies in the literature.

\section{MATERIAL AND METHODS}

\section{Patients}


We retrospectively included all consecutive patients who had a surgical PH repair at the Saint

Antoine's hospital (Paris, France) between April 2001 and July 2017. All patients had undergone an APR for cancer as an index surgery (rectal adenocarcinoma or squamous cell carcinoma of the anus). For each patient, we recorded demographic data (age, gender and comorbidities), first operation data (tumor type and size, resection and reconstruction type, and postoperative follow up), PH symptoms and date of diagnosis, PH repair surgery (hernia size, approach and type of repair) and follow up (recurrence and morbidity as defined by the Clavien Dindo's classification [6]). Pathological staging of the tumor was in accordance with the UICC classification. Patient charts were utilized for data (paper and software), along with imagery software databases, and if needed, patients were contacted directly. All data was anonymized.

\section{PH diagnosis}

PH diagnosis was based on patient reported symptoms (perineal swelling, discomfort, pain) or complications (urinary dysfunction, obstruction and skin erosion), and clinical examination (bulging, impulsive mass in a standing position or with coughing). A CT scan was performed when the clinical diagnosis was questioned. We defined radiological $\mathrm{PH}$ as protrusion of abdominal viscera under the level of coccyx and ischial bones [7] .

A surgical repair was proposed for all patients with a significant symptomatic hernia which impacted on their quality of life or if complications were present due to the PH. Prior to surgery, all patients underwent investigations to out rule a tumor recurrence (clinical examination, extensive CT scan of thorax, abdomen and pelvis and tumor markers).

\section{Surgery}

Surgical repair of PH was based on surgeon preference. The perineal approach was preferentially chosen in the department as it is a less invasive approach associated with a faster recovery. An abdominal approach was mainly used if another procedure was necessary (hysterectomy, incisional or parastomal hernia repair). A biological mesh was commonly used, mainly due to the location of 
the hernia, presence of irradiated tissue and local infection history which raise postoperative mesh

infection risks $[8,9]$.

\section{Perineal approach}

For the perineal approach, patients were placed in prone position. An elliptical incision was made around the previous perineal scar. The hernial sac was dissected and its contents reintroduced into the abdominal cavity. The hernial sac was either resected or closed and left in situ. Dissection was continued to the level of the levator ani muscle insertion. A mesh was cut and adapted to the size of hernial defect and fixed with interrupted non-absorbable sutures laterally to the levator muscle remnant, anteriorly to the pubis and posteriorly to the sacrum and coccyx. Subcutaneous tissue and skin were closed in two layers after a suction drain was placed in contact with the mesh to prevent collections.

\section{Abdominal approach}

When an abdominal approach was chosen, lysis of all adhesions of the abdominal cavity was performed and the perineal hernia content was reintroduced into the abdomen. The mesh was placed and anchored around the pelvic diaphragm (anteriorly to the pubis, prostate and vagina or uterus, laterally to the levator muscle remnant and posteriorly to the coccyx and the sacrum). A vacuum drain was also placed to prevent any postoperative collection.

When judged necessary a vertical rectus abdominis flap (VRAM) was performed in collaboration with a plastic team according to the technique described by Taylor and al. [10, 11].

\section{Postoperative follow up}

When the postoperative course was uneventful, patients were allowed to eat, drink and mobilize, except for patients with a flap reconstruction which necessitated a longer immobilization. Drains were removed when the secretion amount was less than $30 \mathrm{~mL}$ a day or at the surgeon's discretion depending on the output over the previous days. Patients were discharged when they were pain free, had a healing perineal scar without a drain and on normal diet. 
Clinical exam occurred one-month post discharge, with oncological follow up at the surgeon's

discretion.

Early morbidity was defined as any complication during the first 90 postoperative days. Major complication was classified as $\geq 3$ Clavien and Dindo classification score [6]. Recurrence was evaluated according to the patient symptoms and clinical examination. Radiological follow up was performed if a recurrence was suspected.

\section{Literature review}

A systematic review of the literature was performed on the electronic database Pubmed according to the following search terms: "Perineal" and "Hernia ". We limited our search to English and French articles, published between 1960 and June 2017. Articles were selected first by title and abstract. Articles were excluded if the repair technique or the recurrence rate was not reported, if the sample size was $<3$ repairs, case reports and if the article was for primary perineal hernia repair.

\section{RESULTS}

\section{Patient characteristics}

Between April 2001 and July 2017, twenty-one patients underwent perineal hernia repair for a symptomatic or complicated $\mathrm{PH}$ ( 15 women and 6 males). A total of 24 procedures were performed. Median age at the time of repair was 60.5 years old (range: 32-84 years). Preoperative patient characteristics are listed in the Table 1.

Only one patient in the cohort did not receive neoadjuvant treatment (95.2\%). An APR was performed for $14(66.7 \%)$ rectal adenocarcinomas and 7 anal squamous cell carcinomas.

A laparoscopic approach was performed in 11 (52.4\%) index oncological resections. Details of the surgical procedure was known for only 17 patients with an extralevator resection representing $88.2 \%$ of the procedures $(\mathrm{N}=15)$. An omentoplasty was performed for all patients. Pelvic reconstruction consisted of direct closure in two layers for all patients except one who underwent a Gracilis flap. 
Postoperative complications occurred in 9 patients (42.9\%) including 6 perineal wound complications (28.6\%). Eight patients underwent adjuvant treatment $(38.1 \%)$. The pathological reports were available for 18 patients. The mean tumor size was $30 \mathrm{~mm}$ (range 0 to $100 \mathrm{~mm}$ ), $58 \%$ were classified stage 1 or $2(\mathrm{~N}=12)$ and $26 \%$ classified stage 3 or $4(\mathrm{~N}=6)$.

\section{Perineal hernia characteristic (Table 2)}

PH diagnosis was made after a median of 16 months post APR (range 3 - 72 months). Discomfort was the most frequent symptom reported by patients $(87.5 \%)$, followed by increasing swelling size (41.7\%) and pain (12.5\%). PH contents was described during surgery or on preoperative CT scans as small bowel for 16 of the 21 patients (76.2\%), omentum for ten (47.6\%), uterus and/or bladder for six (28.6\%) and colon for two (9.2\%). A PH complication occurred in 10 patients (41.7\%): urinary dysfunction $(n=6)$, skin erosion $(n=2)$ and bowel obstruction $(n=2)$.

Prior to surgical repair of $\mathrm{PH}$, an oncological recurrence was eliminated for all patients by tumor markers and CT scans. A tumor recurrence was diagnosed and treated between the APR and PH diagnosis in two patients: an inguinal recurrence of a squamous cell tumor treated by chemoradiotherapy and nodal resection, and a local recurrence of a rectal adenocarcinoma localized in the labia majora treated by surgical resection and chemotherapy. One further patient had a primary diagnosis of endometrial adenocarcinoma, treated with a total hysterectomy at the time of PH repair. Median hernial defect size, estimated clinically during surgery or in preoperative CT-scans, was 70 mm (Range 35-110 mm).

Surgical repair of PH was performed after a median follow up of 24 months post APR (Range 9-190) and 5.5 months after initial diagnosis of PH (Range 1-166 months).

Among the 21 patients diagnosed with $\mathrm{PH}$, a total of 24 procedures were performed including 3 surgeries for $\mathrm{PH}$ recurrence. A perineal approach was performed for 16 patients (66.7\%), an abdominal approach for 5 patients (20.8\%) and combined for 3 patients (12.5\%). 
The repair techniques included a biological mesh for 17 patients $(70.8 \%)$, a synthetic mesh for 5

patients $(20.8 \%)$ and a flap for 2 patients $(8.3 \%)$. A drain was placed in the perineal cavity for all patients bar two $(91.7 \%)$.

The median operative time was 140 minutes (range 60-495). Median operative time for a perineal approach was 135 minutes (Range 60-190), 160 minutes for an abdominal approach (Range 110380), and 315 minutes for a combined approach.

Overall median length of hospital stay (LOS) was 6 days (Range 3-15). Median LOS for a perineal approach was 5.5 days (Range: 3-12), 7 days for an abdominal approach (Range: 6-12) and 7 days for a combined approach.

\section{Postoperative course}

The median follow-up was 32.4 months from the PH repair (Range 1-75 months) and 60 months from the APR (16-214 months).

No mortality occurred during follow up. Overall morbidity was 37.5\% ( $\mathrm{n}=9)$. A major complication occurred in 3 patients $(12.5 \%)$ : one wound dehiscence on post-operative day one requiring an emergency surgery with mesh repair, one obstruction secondary to a $\mathrm{PH}$ recurrence and one local perineal infection requiring VAC therapy.

Minor complications occurred in 6 patients (25\%): 3 urinary infections and 3 perineal healing complications requiring wick packs to heal. Median complication rate for the perineal approach was $37.5 \%(\mathrm{~N}=6)$ (including 2 major complications), $20 \%$ for the abdominal approach $(\mathrm{N}=1$, a minor complication), and $66.7 \%$ for the combined approach $(\mathrm{N}=2)$. Complications occurred in $35.3 \%$ of biological mesh repairs $(\mathrm{N}=6$, including 2 major complications and 3 perineal healing issues) and $20 \%$ for the synthetic mesh repairs $(\mathrm{N}=1)$. During the entire follow up no mesh had to be removed. A clinical recurrence occurred in ten patients (41.7\%) after a median follow up of 9.2 months (range 1-44.6 months). Recurrences occurred in $47.1 \%$ of biological mesh repairs $(\mathrm{N}=8)$ and $40 \%$ of the synthetic mesh repairs $(\mathrm{N}=2)$. No recurrence occurred in the flap group. Recurrences were seen in 
$50 \%$ of the perineal approach cohort $(n=8)$ and $40 \%$ of the abdominal approach cohort $(\mathrm{N}=2)$. No

recurrence was seen in the combined approach cohort. Results of the different techniques and approaches are summarized in the table 3. The median time to recurrence was 11 months for the biological mesh (between 1 and 43 months) and 27.2 months for the synthetic mesh.

Four patients underwent a major surgical procedure at the time of $\mathrm{PH}$ repair. Two hysterectomies were performed with no perineal hernia recurrence or post-operative complication. One incisional hernia treated by suture repair who subsequently had a PH recurrence 10 months after with no complication, and one incisional and parastomal hernia repaired by a perineal approach with acute urinary retention post op and a $\mathrm{PH}$ recurrence 9 months later.

Only two patients underwent reintervention $(n=3)$ for $\mathrm{PH}$ recurrence, with the majority of patients declining further surgical intervention. Of the two patients who underwent further surgical management, one had a recurrence 44 months after the use of a synthetic mesh following an abdominal approach. A second repair was performed using a biological mesh through a perineal approach.. The patient was free from recurrence after 14 months follow up. The second recurrence occurred in a patient with a biological mesh repair through a perineal approach. This patient had an early recurrence three months after with a further surgery using the same approach and technique. A recurrence occurred one month after this with a concurrent bowel obstruction requiring an emergency surgery. The PH was treated by a combined approach using a Taylor flap with no recurrence reported in this patient after 9 months follow up.

When recurrence of $\mathrm{PH}$ was excluded in analysis, there was no difference in the $\mathrm{PH}$ recurrence rate: $42.9 \%$ for all surgeries, $50 \%$ and $40 \%$ for the perineal and abdominal approaches, and $46.7 \%$ and $40 \%$ for biological and synthetic meshes, respectively. Similarly, there was no difference in complication rates: $28.6 \%$ for all surgeries, $28.6 \%$ for the perineal approach and $26.7 \%$ for the biological mesh. 


\section{Literature review}

Following a literature review, twelve studies describing the management of secondary PH were published between 1964 and 2016 [1, 2, 4, 5, 12-19]. Median population size was $8.5(\mathrm{n}=130$ patients of which 138 surgeries were performed). Details of pooled studies are given in table 4 . The perineal approach $(n=79)$ and the use of synthetic prosthesis $(n=79)$ was the commonest approach and technique performed. Recurrence rates ranged from 0 to $66.7 \%$ with a mean recurrence rate of $28 \%$. Recurrence rates were $14.3 \%$ for a flap repair, $24.1 \%$ for a synthetic mesh repair and $36.4 \%$ for a biological mesh repair. According to pooled results found in the literature, an abdominal or laparoscopic approach with synthetic mesh repair is associated with less recurrences (8.3 and $12.5 \%$ respectively) and complications rates (30\% and 9.5\% respectively). Only four studies had a followup $>24$ months $[1,2,8,14]$, with five studies having no follow up reported or follow up of $<12$ months.

\section{DISCUSSION}

Due to improvements in surgical technologies and neoadjuvant treatments, the indications of APR have decreased. APR is still indicated for rectal adenocarcinomas invading the sphincter complex post neoadjuvant treatment and resistance or recurrence of anal squamous cell carcinoma following radio and chemotherapy. $\mathrm{PH}$ represents a late but rare complication of APR. Real incidence of PH after APR remains unknown and is probably underestimated in historical reports $(<1 \%$ for symptomatic and $<7 \%$ for asymptomatic) [5] [1-3]. The decrease in APR indications is balanced by an aggressive attitude in the treatment of rectal and anal tumors (larger surgical resection and more intense neoadjuvant regime) and the use of laparoscopic surgery which is a suggested PH risk factors $[5,8,9,20]$. More recent studies show incidences of 1 to $26 \%$ after oncological resection $[4,5,21]$ The real incidence of $\mathrm{PH}$ remains unclear, with heterogeneity seen in the populations reported in previous studies. 
Since the first PH repair described by Yeomans in 1939, many repair methods have been reported

and have ultimately been based on the type of approach and technique of defect closure used. As this is a rare complication of APR, the literature is mostly composed of case reports or studies of small population size and poor methodology (short follow up and postoperative complications often not describe). Furthermore, in small population studies, authors may have the tendency to publish preferentially good results. No consensus on the optimal operative method to repair PH after APR can be established from the current literature.

Recurrences following PH repair are high in some studies with rates up to $66 \%$ with no repair technique significantly reducing recurrence rates. The abdominal approach seems to have less recurrence than the perineal approach (respectively $40 \%$ versus $50 \%$ in the present study and $15 \%$ versus $38 \%$ in the literature). Advantages to the abdominal approach include better exposure, the ability to perform another procedure at the time of repair and perform a diagnostic exploration of the abdomen to assess oncological recurrence. However, the postoperative recovery may be longer. (extended operative time and hospitalization length of stay, more painful approach and increased risk of post-operative ileus). The perineal approach seems to be the less invasive method with a faster postoperative recovery as operative time is reduced and the risk of postoperative ileus is lower. Furthermore, re-opening the abdominal scar is not required reducing the risk of wound hernia. However, good knowledge of the pelvic region anatomy is needed to fix the mesh sparing nerve, vessels and ureteral damage. The limited exposure associated with this approach may make mesh fixation difficult leading to the increased risk of recurrence $[2,17]$. It seems to be an interesting first approach for small hernia or patient with significant comorbidities. Our department did not perform PH repair by a laparoscopic approach. A laparoscopic approach has been reported in the literature, with 27 patients in the literature review performed in this study (representing $19.5 \%$ of the 138 patients) undergoing a laparoscopic approach with a recurrence rate of $14.8 \%$. It seems to be an interesting and achievable approach, but patient selection is paramount. This approach is not suitable 
for large hernia or patient with multiple prior surgeries with high risk of small bowel injury. No data

on robotic approach have been published so far.

Similar recurrence rates are seen in the type of mesh (biological or synthetic) used (47.1\% versus $40 \%$ in the present study and $36.4 \%$ versus $24.1 \%$ in the literature). Due to their expensive cost, biological mesh must be reserved for high risk populations (long history of chronic pelvic sepsis, high irradiated tissues, enterocutaneous fistula and bowel injury during dissection). Some authors have suggested that biological mesh could contribute to late recurrences due to their slow and progressive resorption. [16]. However, the use of synthetic mesh remains a good option in the absence of pelvic floor infection and when the peritoneum can be totally closed. Synthetic mesh repair is associated with complications including bowel obstruction, fistulas and may complicate a future reintervention. There is paucity in the literature with regard to mesh complications post PH repair currently. More studies are needed to investigate the complications of each form of mesh repair.

Flap reconstructions have good results (14.3\% recurrence rate) but must be reserved for complex or recurrent $\mathrm{PH}$ in patients fit for a more invasive surgical repair (increased operative time, postoperative immobilization, donor-site morbidity and complication rate). Myocutaneous flaps seem to be more expensive than a biological mesh due to the cost of the hospitalization, patient immobilization and nursing [22]. VRAM flaps have been shown to reduce PH post APR perineal repair compared with mycocutaneous or fasciocutaneous gluteal flaps [23].

Limitations of the present study include its retrospective nature with a small sample size. The methedology restriction is due to the rarity of $\mathrm{PH}$ and the necessity to include patients for a long period. However, this study adds to the limited literature currently on the topic of PH management, presenting concise outcome data on the different approaches and techniques for repair. Recurrence rates in the present study are higher than in previous reports (mean recurrence rate of $27 \%$ in the literature versus $37.5 \%$ in the present study). This difference can be explained by the absence of consensual definition of recurrence (based only on patient feeling pain or discomfort, clinical examination or radiological imagery). Clinical diagnosis of hernia is complex in patients with chronic 
pain and perineal wound inflammation secondary to multiple surgeries and radiotherapy. Some

patients with recurrence still complained of symptoms post PH repair. Furthermore, some patients attribute functional symptoms to the initial hernia despite full resolution and repair of the $\mathrm{PH}$. We limited our inclusion criteria to APR for cancer, although, some articles included APR for inflammatory bowel disease. An oncological resection requiring wider margins could influence results leading to bigger $\mathrm{PH}$ defects and may influence the tissue available for anchoring the mesh during the repair. Previous studies also failed to report complications and used different definitions of PH which further adds to the differences seen in the present study.

Follow up in the present study may influence recurrence outcomes. Although median follow up was 25 months, one patient had short follow up (one month). The same problem is found in other studies of the literature with only five studies with a follow up $>24$ months. This follow up might be too short since recurrence can occur after two years following repair. We were not able to pool follow up data based on the technique used as the various articles did not detail this.

More studies are necessary to determine the real incidence of PH after oncological APR and identify risk factor for its occurrence. Many risk factors were investigated: female sex, diabetes, tobaceo, age, obesity, radiotherapy, laparoscopy and perineal wound left open. There is some divergence in the literattre with the majority of risk factors not being able to be avoided. However, better identification of patient PH risk could tailor surgical repairs for individual patients, especially in the reconstruction technique used during the APR. It is assumed that all reconstruction technique of the pelvic floor during APR do not lead to the same PH rate [21, 24]. In our department we routinely perform a VRAM flap reconstruction after APR for anal squamous carcinoma due to the size of the cutaneous resection. This procedure has shown good result in $\mathrm{PH}$ prevention without increasing complication outcomes [11]. For adenocarcinoma populations with high PH risk factor, a similar protocol could be proposed, preventing synthetic mesh placement in perineal reconstruction. However, outcomes of studies assessing biological mesh reconstruction as opposed to synthetic mesh repair after APR are required to highlight the associated complications of both techniques. 


\section{CONCLUSION}

Many PH repair methods have been described in the literature based on the approach (abdominal, perineal, combined or laparoscopic) and technique (suture, pexy, biological or synthetic mesh or flap) of the repair. Due to the paucity of literature on the topic, conclusions on the best repair method can't be drawn as high recurrence rates are found for each technique. More studies are necessary to prevent PH by identifying patients with $\mathrm{PH}$ risk factors and deciding the appropriate perineal reconstruction during index APR. In our daily practice, we prefer a perineal approach with use of a mesh as a first step for PH. In case of recurrence after previous repair or in case of large defect with skin lesion, an abdominal approach with a VRAM give excellent results but with increased morbidity.

\section{REFERENCES}

1. Aboian E, Winter DC, Metcalf DR, Wolff BG. Perineal hernia after proctectomy: prevalence, risks, and management. Dis Colon Rectum 2006; 49: 1564-8.

2. Beck DE, Fazio VW, Jagelman DG, Lavery IC, McGonagle BA. Postoperative perineal hernia. Dis Colon Rectum 1987; 30: 21-4.

3. Hullsiek HE. Perineal hernia following abdominoperineal resection. Am J Surg 1956; 92: 735-8.

4. Martijnse IS, Holman F, Nieuwenhuijzen GA, Rutten HJ, Nienhuijs SW. Perineal hernia repair after abdominoperineal rectal excision. Dis Colon Rectum 2012; 55: 90-5.

5. Sayers AE, Patel RK, Hunter IA. Perineal hernia formation following extralevator abdominoperineal excision. Colorectal Dis 2015; 17: 351-5.

6. Clavien PA, Barkun J, de Oliveira ML, Vauthey JN, Dindo D, Schulick RD, et al. The Clavien-Dindo classification of surgical complications: five-year experience. Ann Surg 2009; 250: 187-96.

7. Narang SK, Alam NN, Kockerling F, Daniels IR, Smart NJ. Repair of Perineal Hernia Following Abdominoperineal Excision with Biological Mesh: A Systematic Review. Front Surg 2016; 3: 49. 
8. Chadwick MA, Vieten D, Pettitt E, Dixon AR, Roe AM. Short course preoperative radiotherapy is the

single most important risk factor for perineal wound complications after abdominoperineal excision of the rectum. Colorectal Dis 2006; 8: 756-61.

9. Bullard KM, Trudel JL, Baxter NN, Rothenberger DA. Primary perineal wound closure after preoperative radiotherapy and abdominoperineal resection has a high incidence of wound failure. Dis Colon Rectum 2005; 48: 438-43.

10. Taylor GI, Corlett R, Boyd JB. The extended deep inferior epigastric flap: a clinical technique. Plast Reconstr Surg 1983; 72: 751-65.

11. Lefevre JH, Parc Y, Kerneis S, Shields C, Touboul E, Chaouat M, et al. Abdomino-perineal resection for anal cancer: impact of a vertical rectus abdominis myocutaneus flap on survival, recurrence, morbidity, and wound healing. Ann Surg 2009; 250: 707-11.

12. Abbas Y, Garner J. Laparoscopic and perineal approaches to perineal hernia repair. Tech Coloproctol 2014; 18: 361-4.

13. Allen SK, Schwab K, Day A, Singh-Ranger D, Rockall TA. Laparoscopic repair of postoperative perineal hernia using a two-mesh technique. Colorectal Dis 2015; 17: O70-3.

14. Musters GD, Lapid O, Stoker J, Musters BF, Bemelman WA, Tanis PJ. Is there a place for a biological mesh in perineal hernia repair? Hernia 2016; 20: 747-54.

15. Goedhart-de Haan AM, Langenhoff BS, Petersen D, Verheijen PM. Laparoscopic repair of perineal hernia after abdominoperineal excision. Hernia 2016; 20: 741-6.

16. Mjoli M, Sloothaak DA, Buskens CJ, Bemelman WA, Tanis PJ. Perineal hernia repair after abdominoperineal resection: a pooled analysis. Colorectal Dis 2012; 14: e400-6.

17. So JB, Palmer MT, Shellito PC. Postoperative perineal hernia. Dis Colon Rectum 1997; 40: 954-7.

18. Dulucq JL, Wintringer P, Mahajna A. Laparoscopic repair of postoperative perineal hernia. Surg Endosc 2006; 20: 414-8.

19. Ego-Aguirre E, Spratt JS, Jr., Butcher HR, Jr., Bricker EM. Repair of Perineal Hernias Developing Subsequent to Pelvic Exenteration. Ann Surg 1964; 159: 66-71.

20. Stone HB, Coleman CN, Anscher MS, McBride WH. Effects of radiation on normal tissue: consequences and mechanisms. Lancet Oncol 2003; 4: 529-36. 
21. Musters GD, Klaver CEL, Bosker RJI, Burger JWA, van Duijvendijk P, van Etten B, et al. Biological Mesh Closure of the Pelvic Floor After Extralevator Abdominoperineal Resection for Rectal Cancer: A Multicenter Randomized Controlled Trial (the BIOPEX-study). Ann Surg 2017; 265: 1074-81.

22. Peacock O, Pandya H, Sharp T, Hurst NG, Speake WJ, Tierney GM, et al. Biological mesh reconstruction of perineal wounds following enhanced abdominoperineal excision of rectum (APER). Int J Colorectal Dis 2012; 27: 475-82.

23. Foster JD, Pathak S, Smart NJ, Branagan G, Longman RJ, Thomas MG, et al. Reconstruction of the perineum following extralevator abdominoperineal excision for carcinoma of the lower rectum: a systematic review. Colorectal Dis 2012; 14: 1052-9.

24. Christensen HK, Nerstrom P, Tei T, Laurberg S. Perineal repair after extralevator abdominoperineal excision for low rectal cancer. Dis Colon Rectum 2011; 54: 711-7. 


\section{Characteristics}

$\mathrm{N}=21$

Gender (M/F)

$6 / 15$

Age (y)

$60.5(32-84)$

BMI

23.6(20-45)

Neoadjuvant treatment

Long course radiotherapy

Short course radiotherapy

Primary disease N (\%)

Adenocarcinoma

Squamous cell carcinoma

Stage

I-II

III-IV

NA

Tumoral size (mm)

Resection R1

Laparoscopy

Omentoplasty

Perineal closure

$20(95.2 \%)$

$16(76.2 \%)$

$4(19 \%)$

$14(66.7 \%)$

$7(33.3 \%)$

$12(58 \%)$

$6(26 \%)$

$3(14.3 \%)$

$30(0-100)$

$0(0 \%)$

$11(52.4 \%)$

$21(100 \%)$

$3 / 17$

$(17.6 \%)$

Pelvic reconstruction

Simple suture

Muscle flap

$20(95.2 \%)$

$1(4.8 \%)$

Adjuvant treatment

$8(38.1 \%)$

Complications post APR

$9(42.9 \%)$

$6(28.6 \%)$

$16(3-72)$

Interval APR/PH diagnosis (month)

$5.5(1-166)$

Continuous variables are given as median (IQR)

Table 1. Patient and tumor characteristics. 


\begin{tabular}{lr}
\hline Symptoms & $\mathbf{N}(\%)$ \\
\hline Discomfort & $21(87.5 \%)$ \\
Pain & $3(12.5 \%)$ \\
Increasing size & $10(41.7 \%)$ \\
Urinary trouble & $6(25 \%)$ \\
Skin erosion & $2(8.3 \%)$ \\
Bowel obstruction & $2(8.3 \%$ \\
\hline
\end{tabular}

Table 2. Perineal hernia symptoms before surgical repair $(\mathrm{N}=24)$. 


\begin{tabular}{|c|c|c|c|c|c|c|c|c|}
\hline $\begin{array}{l}16 \\
17 \\
18 \\
19\end{array}$ & & & & & & & & \\
\hline $\begin{array}{l}20- \\
21 \\
22 \\
23 \\
24\end{array}$ & & $\begin{array}{c}\text { Tot } \\
\mathrm{N}(\%)\end{array}$ & $\begin{array}{l}\text { Operation time } \\
\text { med min (IQR) }\end{array}$ & $\begin{array}{c}\text { Hospitalization } \\
\text { length of stay med } \\
\text { day (IQR) }\end{array}$ & $\begin{array}{c}\text { Complications } \\
\text { N (\%) }\end{array}$ & $\begin{array}{c}\text { Recurrences } \mathrm{N} \\
(\%)\end{array}$ & $\begin{array}{c}\text { Interval PH } \\
\text { repair/recurrence } \\
\text { month med (IQR) }\end{array}$ & $\begin{array}{l}\text { Follow up month } \\
\text { med (IQR) }\end{array}$ \\
\hline $\begin{array}{l}25 \\
26\end{array}$ & Approach type & & & & & & & \\
\hline $\begin{array}{l}27 \\
28\end{array}$ & Perineal & $16(66.7 \%)$ & $135(60-190)$ & $5.5(3-12)$ & $6(37.5 \%)$ & $8(50 \%)$ & $7.9(1-43)$ & $26.4(1-64)$ \\
\hline 29 & Abdominal & $5(20.8 \%)$ & $160(110-380)$ & $7(6-12)$ & $1(20 \%)$ & $2(40 \%)$ & $27(9-44)$ & $25(1-45)$ \\
\hline 31 & Combined & $3(12.5 \%)$ & $315(150-495)$ & $7(7-15)$ & $2(66.7 \%)$ & $0(0 \%)$ & - & $50(16-75)$ \\
\hline 33 & Technique repair & & & & & & & \\
\hline 35 & Biological mesh & $17(70.8 \%)$ & $138(60-380)$ & $6(3-12)$ & $6(35.3 \%)$ & $8(47.1 \%)$ & $11(1-43)$ & $25(1-64)$ \\
\hline $\begin{array}{l}36 \\
37\end{array}$ & Synthetic mesh & $5(20.8 \%)$ & $150(110-185)$ & $7(6-7)$ & $1(20 \%)$ & $2(40 \%)$ & $27.2(9-44)$ & $16(1-45)$ \\
\hline $\begin{array}{l}38 \\
39\end{array}$ & Muscle flap & $2(8.3 \%)$ & $405(315-495)$ & $11(7-15)$ & $2(100 \%)$ & $0(0 \%)$ & - & $63(50-75)$ \\
\hline $\begin{array}{l}40^{-} \\
41\end{array}$ & Total & $24(100 \%)$ & $140(60-495)$ & $6(3-15)$ & $9(37.5 \%)$ & $10(41.7 \%)$ & $9.2(1-44)$ & $29(1-75)$ \\
\hline
\end{tabular}

Table 3. Hernial repair: recurrences and complications after 24 procedures. 


\begin{tabular}{|c|c|c|c|c|c|}
\hline & $\begin{array}{l}\text { Raphie/Pexy/ } \\
\text { graft/other }\end{array}$ & $\begin{array}{c}\text { Synthetic } \\
\text { mesh }\end{array}$ & $\begin{array}{l}\text { Biologic } \\
\text { Mesh }\end{array}$ & Flap & Total \\
\hline \multicolumn{6}{|l|}{ Abdominal } \\
\hline $\mathrm{N}$ & 4 & 12 & 2 & - & 20 \\
\hline Recurrence & $0 / 4(0 \%)$ & $1 / 12(8.3 \%)$ & $0 / 2(0 \%)$ & & $3 / 20(15 \%)$ \\
\hline Complication & $0 / 2(0 \%)$ & $3 / 10(30 \%)$ & $0 / 1(0 \%)$ & & $4 / 15(26.7 \%)$ \\
\hline \multicolumn{6}{|l|}{ Perineal } \\
\hline $\mathrm{N}$ & 19 & 42 & 14 & 4 & 79 \\
\hline Recurrence & $8 / 19(42.1 \%)$ & $15 / 42(35.7 \%)$ & $7 / 14(50 \%)$ & $0 / 4(0 \%)$ & $30 / 75(38 \%)$ \\
\hline Complication & $5 / 9(55.6 \%)$ & $8 / 37(21.6 \%)$ & $0 / 2(0 \%)$ & UNK & $12 / 48(27.1 \%)$ \\
\hline \multicolumn{6}{|l|}{ Laparoscopic } \\
\hline $\mathrm{N}$ & 2 & 24 & 1 & - & 27 \\
\hline Recurrence & $1 / 2(50 \%)$ & $3 / 24(12.5 \%)$ & $0 \%$ & & $4 / 27(14.8 \%)$ \\
\hline Complication & UNK & $2 / 21(9.5 \%)$ & UNK & & $2 / 21(9.5 \%)$ \\
\hline \multicolumn{6}{|l|}{ Combined } \\
\hline $\mathrm{N}$ & 3 & 1 & - & - & 4 \\
\hline Recurrence & $0 / 3(0 \%)$ & $0 / 1(0 \%)$ & & & $0 / 4(0 \%)$ \\
\hline Complication & UNK & UNK & & & UNK \\
\hline \multicolumn{6}{|l|}{ Total } \\
\hline $\mathrm{N}$ & 28 & 79 & 22 & 7 & 138 \\
\hline Recurrence & $9 / 28(32.1 \%)$ & $19 / 79(24.1 \%)$ & $8 / 22(36.4 \%)$ & $1 / 7(14.3 \%)$ & $39 / 138(28.3 \%)$ \\
\hline Complication & $5 / 11(45.5 \%)$ & $13 / 68(19.1 \%)$ & $0 / 3(0 \%)$ & UNK & $19 / 84(22.6 \%)$ \\
\hline
\end{tabular}

Table 4. Literature review pooled results of surgical repair of perineal hernia. 


\begin{tabular}{|c|c|c|c|c|}
\hline First author & Patients & $\begin{array}{c}\text { Technic } \\
\text { (Approach/Method) }\end{array}$ & Recurrence \% & $\begin{array}{c}\text { Complication } \\
\% \\
\end{array}$ \\
\hline Ego-aguirre [19] & $\mathrm{N}=9$ & $\begin{array}{l}\text { Perineal/Suture } \mathrm{N}=6 \\
\text { Perineal/Synthetic } \mathrm{N}=3 \\
\text { Redo surgery } \\
\text { Perineal/Suture } \mathrm{N}=3 \\
\text { Perineal/Synthetic } \mathrm{N}=1 \\
\text { Abdominal N=2 }\end{array}$ & $\begin{array}{c}66.7 \%(4) \\
66.7 \%(2) \\
66.7(2) \\
0 \% \\
100 \%(2)\end{array}$ & $\begin{array}{c}50 \%(3) \\
66.7 \%(2) \\
\\
\\
0 \% \\
50 \%(1)\end{array}$ \\
\hline Beck [2] & $\mathrm{N}=10$ & $\begin{array}{l}\text { Perineal/Synthetic } \mathrm{N}=2 \\
\text { Abdominal/Synthetic } \mathrm{N}=8\end{array}$ & $\begin{array}{l}100 \%(2) \\
12.5 \%(1)\end{array}$ & $\begin{array}{c}0 \% \\
37.5 \%(3) \\
\end{array}$ \\
\hline Allen [13] & $\mathrm{N}=6$ & $\begin{array}{l}\text { Laparoscopy/Synthetic } \mathrm{N}=5 \\
\text { Combined/Synthetic } \mathrm{N}=1\end{array}$ & $\begin{array}{l}0 \% \\
0 \%\end{array}$ & $33.3 \%(2)$ \\
\hline Musters [14] & $\mathrm{N}=15$ & $\begin{array}{l}\text { Perineal/Biologic } \mathrm{N}=11 \\
\text { Perineal/Flap } \mathrm{N}=3 \\
\text { Abdominal/Biologic } \mathrm{N}=1\end{array}$ & $\begin{array}{c}63,6 \%(7) \\
0 \% \\
0 \%\end{array}$ & $20 \%(3)$ \\
\hline So [17] & $\mathrm{N}=19$ & $\begin{array}{l}\text { Perineal/Synthetic } \mathrm{N}=4 \\
\text { Perineal/Suture } \mathrm{N}=8 \\
\text { Perineal/Flap } \mathrm{N}=1 \\
\text { Abdominal/Synthetic } \mathrm{N}=1 \\
\text { Abdominal/Suture } \mathrm{N}=2 \\
\text { Combined/Suture } \mathrm{N}=3 \\
\end{array}$ & $\begin{array}{c}25 \%(1) \\
25 \%(2) \\
0 \% \\
0 \% \\
0 \% \\
0 \% \\
\end{array}$ & $21.1 \%(4)$ \\
\hline Aboian [1] & $\mathrm{N}=8$ & $\begin{array}{l}\text { Abdominal/Suture } \mathrm{N}=2 \\
\text { Abdominal/Synthetic } \mathrm{N}=2 \\
\text { Perineal/Suture } \mathrm{N}=2 \\
\text { Perineal/Synthetic } \mathrm{N}=2\end{array}$ & $0 \%$ & $\begin{array}{c}0 \% \\
0 \% \\
50 \%(1) \\
50 \%(1)\end{array}$ \\
\hline Martijnse [4] & $\mathrm{N}=29$ & Perineal/Synthetic N=29 & $31 \%(9)$ & $17.2(5)$ \\
\hline Mjoli [16] & $\mathrm{N}=3$ & $\begin{array}{l}\text { Perineal/Biologic } \mathrm{N}=2 \\
\text { Abdominal/Biologic } \mathrm{N}=1\end{array}$ & $\begin{array}{l}0 \% \\
0 \%\end{array}$ & $\begin{array}{l}0 \% \\
0 \%\end{array}$ \\
\hline Abbas [12] & $\mathrm{N}=7$ & $\begin{array}{l}\text { Laparoscopy/Synthetic } \mathrm{N}=3 \\
\text { Laparoscopy/Biologic } \mathrm{N}=1 \\
\text { Laparoscopy/Suture } \mathrm{N}=1 \\
\text { Perineal/Biologic } \mathrm{N}=1 \\
\text { Abdominal/Synthetic } \mathrm{N}=1\end{array}$ & $0 \%$ & $14.3 \%(1)$ \\
\hline $\begin{array}{l}\text { Goedhart-de Haan } \\
{[15]}\end{array}$ & $\mathrm{N}=12$ & $\begin{array}{l}\text { Laparoscopy/Synthetic } \\
\mathrm{N}=12\end{array}$ & $25 \%(3)$ & $8.3 \%(1)$ \\
\hline Sayers [5] & $\mathrm{N}=8$ & $\begin{array}{l}\text { Biologic } \mathrm{N}=5 \\
\text { Flap } \mathrm{N}=3\end{array}$ & $\begin{array}{c}20 \%(1) \\
33.3 \%(1)\end{array}$ & UNK \\
\hline Dulucq [18] & $\mathrm{N}=4$ & $\begin{array}{l}\text { Laparoscopy/Synthetic } \mathrm{N}=4 \\
\text { Laparoscopy/Suture } \mathrm{N}=1 \\
\text { Perineal/Synthetic } \mathrm{N}=1\end{array}$ & $\begin{array}{c}0 \% \\
100 \%(1) \\
100 \%(1)\end{array}$ & $\begin{array}{l}0 \% \\
\text { UNK } \\
\text { UNK }\end{array}$ \\
\hline
\end{tabular}

Table 5. Literature review detail. 


\section{Please wait...}

If this message is not eventually replaced by the proper contents of the document, your PDF viewer may not be able to display this type of document.

You can upgrade to the latest version of Adobe Reader for Windows®, Mac, or Linux® by visiting http://www.adobe.com/go/reader_download.

For more assistance with Adobe Reader visit http://www.adobe.com/go/acrreader.

Windows is either a registered trademark or a trademark of Microsoft Corporation in the United States and/or other countries. Mac is a trademark of Apple Inc., registered in the United States and other countries. Linux is the registered trademark of Linus Torvalds in the U.S. and other countries. 


\section{Please wait...}

If this message is not eventually replaced by the proper contents of the document, your PDF viewer may not be able to display this type of document.

You can upgrade to the latest version of Adobe Reader for Windows®, Mac, or Linux® by visiting http://www.adobe.com/go/reader_download.

For more assistance with Adobe Reader visit http://www.adobe.com/go/acrreader.

Windows is either a registered trademark or a trademark of Microsoft Corporation in the United States and/or other countries. Mac is a trademark of Apple Inc., registered in the United States and other countries. Linux is the registered trademark of Linus Torvalds in the U.S. and other countries. 


\section{Please wait...}

If this message is not eventually replaced by the proper contents of the document, your PDF viewer may not be able to display this type of document.

You can upgrade to the latest version of Adobe Reader for Windows®, Mac, or Linux® by visiting http://www.adobe.com/go/reader_download.

For more assistance with Adobe Reader visit http://www.adobe.com/go/acrreader.

Windows is either a registered trademark or a trademark of Microsoft Corporation in the United States and/or other countries. Mac is a trademark of Apple Inc., registered in the United States and other countries. Linux is the registered trademark of Linus Torvalds in the U.S. and other countries. 


\section{Please wait...}

If this message is not eventually replaced by the proper contents of the document, your PDF viewer may not be able to display this type of document.

You can upgrade to the latest version of Adobe Reader for Windows®, Mac, or Linux® by visiting http://www.adobe.com/go/reader_download.

For more assistance with Adobe Reader visit http://www.adobe.com/go/acrreader.

Windows is either a registered trademark or a trademark of Microsoft Corporation in the United States and/or other countries. Mac is a trademark of Apple Inc., registered in the United States and other countries. Linux is the registered trademark of Linus Torvalds in the U.S. and other countries. 


\section{Please wait...}

If this message is not eventually replaced by the proper contents of the document, your PDF viewer may not be able to display this type of document.

You can upgrade to the latest version of Adobe Reader for Windows®, Mac, or Linux® by visiting http://www.adobe.com/go/reader_download.

For more assistance with Adobe Reader visit http://www.adobe.com/go/acrreader.

Windows is either a registered trademark or a trademark of Microsoft Corporation in the United States and/or other countries. Mac is a trademark of Apple Inc., registered in the United States and other countries. Linux is the registered trademark of Linus Torvalds in the U.S. and other countries. 


\section{Please wait...}

If this message is not eventually replaced by the proper contents of the document, your PDF viewer may not be able to display this type of document.

You can upgrade to the latest version of Adobe Reader for Windows®, Mac, or Linux® by visiting http://www.adobe.com/go/reader_download.

For more assistance with Adobe Reader visit http://www.adobe.com/go/acrreader.

Windows is either a registered trademark or a trademark of Microsoft Corporation in the United States and/or other countries. Mac is a trademark of Apple Inc., registered in the United States and other countries. Linux is the registered trademark of Linus Torvalds in the U.S. and other countries. 


\section{Please wait...}

If this message is not eventually replaced by the proper contents of the document, your PDF viewer may not be able to display this type of document.

You can upgrade to the latest version of Adobe Reader for Windows®, Mac, or Linux® by visiting http://www.adobe.com/go/reader_download.

For more assistance with Adobe Reader visit http://www.adobe.com/go/acrreader.

Windows is either a registered trademark or a trademark of Microsoft Corporation in the United States and/or other countries. Mac is a trademark of Apple Inc., registered in the United States and other countries. Linux is the registered trademark of Linus Torvalds in the U.S. and other countries. 